\section{THU0736-HPR EFFICACY OF DIFFERENT TYPES OF EXERCISE PROGRAMS IN OSTEOPOROSIS WITH HIGH RISK OF FALLS}

K. Kazár-Tóth ${ }^{1}$, C.K. Karóczi ${ }^{1}$, B. Monek ${ }^{1}$, C. Gácserné ${ }^{1}$, É. Kovács ${ }^{2}$, G. Poór ${ }^{1}$ I. Mikó ${ }^{1} .{ }^{1}$ National Institute of Rheumatology and Physiotherapy; ${ }^{2}$ Semmelweis University, Institute for Applied Health Sciences, Budapest, Hungary

Background: While ageing the frequency of osteoporosis increases. The most frequent risk factor is falling and consequently bone fractures which in this population is associated with high mortality. According to WHO data, $28-35 \%$ of elderly over 65 years falls at least once per year, which increases to $32-47 \%$ over 70 years.

Objectives: The purpose of this randomized control study was to investigate the efficacy of a land-based and water-based exercise program specifically targeting balance to reduce fall risk in patients over 65 years with osteoporosis. We assumed that water-based training program would develop balance efficiently even at elderly people with severe degenerative diseases. Coordination in water is possible to be developed efficiently.

Methods: The study was carried out in the National Institute of Rheumatology and Physiotherapy. 61 participants were randomized $[\mathrm{n}=20$ sensorimotor training group, $n=20$ control group (CG)] in the land-based sensorimotor training program (SMT) and 21 people [ $n=7$ Ai Chi group (AC), $n=7$ water adapted sensorimotor training group (WASM), $n=7$ control group] in the water-based training program (WBT). The control group did not participate in any training program. The exclusion criteria were neurological, cardiovascular and musculoskeletal diseases, which contraindicated the participation in the training program. Functional Reach Test (FRC), Timed Up and Go Test (TUG), Star Excursion Balance Test (SEBT) and coordination test by stabilometer were used to measure static and dynamic balance. The measurements were performed before and after the training period. The results of the SMT were analyzed with two-sample t-test, and the results of the WBT with non-parametrical methods. The results were defined with $p<0,05$ statistical margin by SPSS program.

Results: After 18-weeks of the SMT program significant improvement was experienced in the SMT group compared to the CG with the following parameters: FRC $(p<0.001)$, TUG $(p=0.01)$. In the coordination test no significant difference was found between the SMT and the CG $(p=0.09)$. After 8 -weeks of the WBT programs significant improvement in the mediolateral direction of SEBT was detected in the WASM $(p=0.028)$ and in the AC group $(p=0.043)$ compared to the CG. FRC test was shown marginal significance $(p=0.075)$ in the WASM group, while at the $A C$ group remarkable improvement $(p=0.043)$ was recognised compared to the CG. In the TUG test significant improvement was found in the $C G$ and the WASM ( $p=0.028, p=0.043)$ compared to the CG.

Conclusions: The findings from this study support the efficacy of the land- and water-based exercise programs in improving balance in this sample. Our results pointed out that balance improved efficiently even at degenerative joint diseases. Limitations of our research was the small number of the participants and the short duration of the program. In the light of the promising outcome we will continue our research that would result in an efficient fall prevention in this population with high risk of falling.

References:

[1] Sherrington C, Tiedemann A, Fairhall N, Close JC, Lord SR. (2011). Exercise to prevent falls in older adults: an updated meta-analysis and best practice recommendations. NSW Public Health Bulletin, Vol. 22(3-4): 78-83.

Disclosure of Interest: None declared

DOI: 10.1136/annrheumdis-2017-eular.3783

\section{THU0737-HPR EXPERIENCES AND APPRECIATION OF SHARED MEDICAL APPOINTMENT OF YOUNG ADULTS WITH A RHEUMATIC DISEASE, IN TRANSITION FROM CHILD TO ADULT CARE}

L. Gossens ${ }^{1}$, J. Ammerlaan ${ }^{1}$, L. Cazemier ${ }^{1}$, H. Bouwens ${ }^{2}$, B. Formsma ${ }^{2}$, J. van Laar ${ }^{1}$, A. Kruize ${ }^{1} .{ }^{1}$ Rheumatology and Clinical Immunology; ${ }^{2}$ Patient partner, UMC Utrecht, Utrecht, Netherlands

Background: Young adults with rheumatic diseases deal with questions and uncertainties since their disease and treatment affect both physical and socioemotional development ${ }^{1,2}$. As part of the transition from child to adult care, the UMC Utrecht offers a shared medical appointment (SMA). During a SMA, four to six patients are seen together in the presence of a doctor and nurse specialist. Compared to an individual consultation with a doctor or nurse, a SMA is offering extensive exchange of information and shared experiences focussed on everyday life, as sport, study, work and treatment ${ }^{3}$. During a SMA, patients learn from each other, which supports self-management. In practice, the care providers notice that young adults are reluctant to join a SMA, they hesitate to have a consultation in presence of their peers. When invited, most patients, however, do attend a SMA, and it is unknown how these young adults experience and appreciate the SMA. This evaluation is a first step of a larger project. The results will be deepened and supplemented with the findings on interviews with young adults and professionals, in order to give an advice for further development of the SMA in our clinic.

Objectives: Evaluating experiences and appreciation of SMA in transition patients in order to further develop the SMA in our clinic.

Methods: In the period of January 2014 till December 2016, patients in transition who participated in SMA were asked to fill in an evaluation questionnaire. This questionnaire focussed on expectations, quality of medical care compared to an individual consultation, information about disease and treatment during a SMA and the presence of other young adults. Data was analysed by the researchers and patient partners using SPSS and thematic analysis.

Results: Forty-five patients filled in the evaluation questionnaire, among them 35 women, with an average age of 19.6 years. The majority had a form of juvenile idiopathic arthritis $(n=39)$; with average disease duration of 9,4 years and most were using a DMARD and/or biological $(n=35)$. The results showed that participating patients were just as satisfied with the medical care in a SMA compared to a regular consultation; they indicate that more information was given in a SMA and the presence of peers was experienced as pleasant. Most appreciated were sharing experiences, individual stories and tips. Personal attention and lack of privacy were perceived as less pleasant, moreover young adults expressed to find it difficult to discuss personal issues.

Conclusions: Although it is difficult to motivate the young adults to attend the SMA, whenever they do attend, they appreciate a SMA in positive way, especially on benefits of sharing information and meeting peers, when offered in addition to individual consultations with doctor and nurse.

\section{References:}

[1] Ammerlaan JW, Scholtus LW, Bijlsma JWJ, Prakken ABJ, Kruize AA. An urge for change: Transitional care for young adults with juvenile idiopathic arthritis. Patient Education and Counseling 2013;92:127-129.

[2] Foster HE, Minden K, Clemente D, Leon L, McDonagh JE, et al. EULAR/PReS standards and recommendations for the transitional care of young people with juvenile-onset rheumatic diseases. Ann Rheum Dis 2016;0:1-8.

[3] Noffsinger E. Running group visits in your practice. New York: Springer, 2009. Disclosure of Interest: None declared

DOI: 10.1136/annrheumdis-2017-eular.3257

\section{THU0738-HPR PROMOTING PHYSICAL ACTIVITY IN RHEUMATOID ARTHRITIS: DEVELOPING A THEORY-BASED BEHAVIOUR CHANGE INTERVENTION}

L. Larkin ${ }^{1}$, A. Fraser ${ }^{2}$, S. Gallagher ${ }^{3}$, N. Kennedy ${ }^{1} .{ }^{1}$ Department of Clinical Therapies, University of Limerick; ${ }^{2}$ Department of Rheumatology, University Hospitals Limerick; ${ }^{3}$ Department of Psychology, University of Limerick, Limerick, Ireland

Background: Physical activity has numerous benefits for people who have RA, however interventions targeting physical activity behaviour in people who have RA have had limited efficacy [1]

Objectives: To develop a theory-based behaviour change intervention to promote physical activity in people who have RA.

Methods: Development was guided by the UK's Medical Research Council Complex Interventions framework [2] and consisted of three components;

1. Narrative review which explored the use of behaviour change theory in previous interventions

2. Systematic review which examined the content and structure of previous interventions

3. Qualitative study which explored the preferences of key stakeholders (people who have RA and health professionals) about the design of the intervention.

Results: Previous interventions lacked consideration of behaviour change theory in design and delivery, and there was a large degree of variance in content, structure and delivery. Lack of knowledge of current physical activity

\begin{tabular}{|c|c|c|}
\hline Intervention & Overview & Detail \\
\hline Aim & Promote physical activity & Time spent in moderate-intensity aerobic activity \\
\hline Participants & Adults (18 years + ), diagnosis of $R A$ & Newly-diagnosed \\
\hline \multirow[t]{2}{*}{$\begin{array}{l}\text { Outcome } \\
\text { measures }\end{array}$} & $\begin{array}{l}\text { Physical activity (time spent in } \\
\text { moderate-intensity ADLs) }\end{array}$ & ActivPAL ${ }^{\mathrm{MM}}$ activity monitor \\
\hline & $\begin{array}{l}\text { Physical activity beliefs, Self-efficacy, } \\
\text { Quality of life, Pain, Fatigue }\end{array}$ & To be determined at protocol stage \\
\hline Mode & Face-to-face & Initial $1: 1$ session, follow-up in group sessions \\
\hline Location & Community location & Local health or community centres \\
\hline Deliverer & Health professional (credible source) & Physiotherapist \\
\hline \multirow[t]{3}{*}{ *Content } & Education & $\begin{array}{l}4.1 \text { Instruction on how to perform a behaviour, } 5.1 \\
\text { Information about health consequences, } 5.2 \\
\text { Salience of consequences, } 1.1 \text { Goal setting } \\
\text { (behaviour), } 1.2 \text { Problem solving }\end{array}$ \\
\hline & Enablement & $\begin{array}{l}1.4 \text { Action planning, } 1.5 \text { Review behaviour goals, } \\
2.2 \text { Feedback on behaviour, } 2.3 \text { Self-monitoring of } \\
\text { behaviour, } 6.1 \text { Demonstration of behaviour, } 6.2 \\
\text { Social comparison }\end{array}$ \\
\hline & Modeling & 8.1 Behavioural practice/rehearsal \\
\hline Control & Education & 1 group information session on physical activity \\
\hline
\end{tabular}

$A D L=$ activities of daily living; $R A=$ Rheumatoid arthritis

*As per Behaviour Change Wheel (Michie et al 2014) 